\title{
Are pharmacists' good knowledge and awareness on antibiotics taken for granted? The situation in Albania and future implications across countries
}

\author{
Iris Hoxha ${ }^{1,2}$, Admir Malaj ${ }^{1}$, Besmira Kraja ${ }^{3}$, Silvia Bino ${ }^{4}$, Margaret Oluka ${ }^{5}$, Vanda Marković-Peković6, \\ Brian Godman $8,9,10$
}

1Department of Pharmacy, Faculty of Medicine, University of Medicine Tirana, Albania. Email:

iris.hoxha@umed.edu.al; admir.malaj@yahoo.it

${ }^{2}$ Focal point of Antimicrobial Consumption, Ministry of Health, Tirana, Albania.

3Pharmacy 24, Shkoder, Albania. Email: besmira 91@live.com

${ }^{4}$ Control of Infectious Diseases Department, Institute of Public Health, Tirana, Albania. Email:

silviabino@gmail.com

${ }^{5}$ Department of Pharmacology \& Pharmacognosy, School of Pharmacy, University of Nairobi, P.O.

Box 19676-00202 KNH, Nairobi, Kenya. Email: olukamarga@yahoo.com

${ }^{6}$ Ministry of Health and Social Welfare, Banja Luka, Republic of Srpska, Bosnia and Herzegovina.

Email:v.mpekovic@mzsz.vladars.net

${ }^{7}$ Department of Social Pharmacy, Medical Faculty, University Banja Luka, Banja Luka, Republic of

Srpska, Bosnia and Herzegovina

${ }^{8}$ Strathclyde Institute of Pharmacy and Biomedical Sciences, University of Strathclyde, Glasgow G4

ORE, United Kingdom. Email: Brian.godman@strath.ac.uk.

${ }^{9}$ Health Economics Centre, University of Liverpool Management School, Liverpool, UK. Email:

Brian.Godman@liverpool.ac.uk

${ }^{9}$ Division of Clinical Pharmacology, Karolinska Institute, Karolinska University Hospital Huddinge, SE141 86, Stockholm, Sweden. Email: Brian.Godman@ki.se.

*Author for correspondence: Strathclyde Institute of Pharmacy and Biomedical Sciences, University of Strathclyde, Glasgow G4 ORE, United Kingdom. Email: Brian.godman@strath.ac.uk. Telephone: 0141548 3825. Fax: 01415522562 and Division of Clinical Pharmacology, Karolinska Institute, Karolinska University Hospital Huddinge, SE-141 86, Stockholm, Sweden. Email:

Brian.Godman@ki.se. Telephone + 468 58581068. Fax + 46859581070

(Accepted for publication in Journal of Global Antimicrobial Resistance - Please keep CONFIDENTIAL)

\footnotetext{
Abstract

Objectives: Irrational use of antibiotics is a major driver of antimicrobial resistance (AMR), exacerbated by dispensing of antibiotics without a prescription especially for typically viral infections. Such dispensing is common despite legislation. Pharmacists play a key role advising on medicines especially in countries where most patients seek pharmacist help as they cannot afford both physician fees and medicines. Consequently, the objective was to ascertain skills and knowledge of pharmacists regarding antibiotics when patients present to them with typically viral infections.

Methods: Qualitative cross-sectional survey among 370 community pharmacists in Albania. Topics carefully selected and validated. Main outcome measure was current knowledge of antibiotics and current legislation. Results: Variable knowledge regarding antibiotics among community pharmacists. $54 \%$ knew colds are caused by viruses and $93 \%$ that antibiotics are ineffective against influenza. However, $18 \%$ believed if colds last for more than 4 days an antibiotic can bring a patient back to work, and only $13 \%$ stated antibiotics are ineffective against viruses. Encouragingly, $92.5 \% \mathrm{knew}$ penicillins can cause anaphylactic shocks, $74 \%$ that antibiotics kill bacteria that cause infections and only $7 \%$ that antibiotic misuse cannot cause AMR. However, $13 \%$ stated the main disadvantage of antibiotics is they are ineffective against viruses and $93 \%$ admitted they had no treatment protocols to consult in their daily work to direct patient care. Conclusion: Encouraging signs regarding pharmacists' knowledge of antibiotics in Albania; however, concerns. Instigating educational programmes among patients and pharmacists and greater enforcement of legislation should reduce AMR rates in Albania and across countries.
} 


\section{Introduction}

Whilst antibiotics have been life saving, the threat of growing resistance rates is becoming a global public health challenge, enhanced by substantially increasing use of antibiotics (1-4). Antimicrobial resistance (AMR) increases morbidity, mortality and costs $(1,2)$, with ongoing global, regional and national initiatives to address rising AMR rates $(1,2)$. These include measures and initiatives to reduce inappropriate prescribing and dispensing of antibiotics for acute respiratory tract infections (ARIs), which are the most common infections in the community and with up to $95 \%$ viral in origin (2, 4-6).

Apart from increasing AMR, over use of antibiotics also increases adverse drug reactions (1). Over use of antibiotics can occur where there is self-purchasing of antibiotics, whether legal or not. Consequently, reducing inappropriate self-purchasing, which is common in many parts of the world (1, $3,5-13$ ), is essential to reduce AMR rates. There are particular issues in low and middle income countries where access to medical care can be limited, difficult to access and costly, and there can be concerns with physician trust $(3,5,7,14)$. As a result, encouraging patients to self-medicate or seek help from professionals such as pharmacists, thereby reducing physician fees $(3,9,10,15)$.

Pharmacists are expected to play a key role with enhancing the appropriate use of medicines $(3,16$, 17), which includes providing appropriate advice for minor ailments such as coughs and colds and reducing unnecessary self-purchasing of antibiotics that still occurs. This especially in countries such as Albania and the Republic of Srpska where pharmacists are seen as the most common source of information regarding medications $(12,18)$.

Concerns that patients are not getting the appropriate advice have resulted in key organisations urging pharmacists to undertake activities to reduce inappropriate dispensing of antibiotics $(19,20)$ (Table 1).

Table 1 - Suggested activities of pharmacists to reduce AMR (adapted from references [19,20])

\begin{tabular}{|c|c|}
\hline FIP & $\begin{array}{l}\text { - Patients should be given proper counselling as well as provided with written } \\
\text { information that is appropriate when dispensing antibiotics. This includes } \\
\text { recommending treatments other than antibiotics for minor conditions such as a } \\
\text { common cold or a sore throat } \\
\text { - Pharmacists should encourage patients to comply with the full prescribed } \\
\text { regimen when dispensed. They should also work with physicians to ensure } \\
\text { patients complete their prescribed/ dispensed course of treatment } \\
\text { Pharmacists should also monitor the supply of antibiotics as well as become } \\
\text { actively involved in promoting hygiene and infection control across health care } \\
\text { settings }\end{array}$ \\
\hline $\begin{array}{l}\text { WHO } \\
\text { Europe }\end{array}$ & $\begin{array}{l}\text { - Pharmacists are seen as an essential player in the health system, which } \\
\text { increasingly includes the funding of pharmaceutical care services } \\
\text { - Whilst pharmacists increasingly take a role in providing relevant information to } \\
\text { - patients to enhance their compliance with a prescribed course of medicine, there } \\
\text { is room to improve the extent and quality of information given to them } \\
\text { - Pharmacists should encourage the prudent use of antibiotics, taking full } \\
\text { advantage of their position as an effective liaison between prescribers and } \\
\text { patients, as well as often being the first contact between patients and healthcare } \\
\text { systems. As a result, help reduce AMR } \\
\text { - Patients should be appropriately counselled on the need for and use of antibiotics } \\
\text { particularly for minor ailments to reduce adverse effects as well as the } \\
\text { consequences of incomplete dosing and growing AMR rates }\end{array}$ \\
\hline
\end{tabular}

Studies have shown that total antibiotic use in Albania varied between 21 to 24 defined daily doses per one thousand inhabitants per day (DIDs) between 2011 and 2014 (17, 21), which was relatively high compared with a number of other Southern and Eastern European countries as well as former Soviet Union Republics $(21,22)$. This is not helped by high rates of self-purchasing of antibiotics in Albania $(78 \%-80 \%)$ despite current legislation (11). Having said this, currently one third of Albanians are not covered by health insurance. Consequently, whilst encouraging greater enforcement of the 
legislation to reduce self-purchasing of antibiotics (11), it is important that pharmacists in Albania give appropriate advice when patients seek care for self-limiting ARIs(Table 1), building on examples in other countries (18). However, there are concerns about the level of education of pharmacists regarding antibiotics (23).

In view of this, there is an urgent need to research whether pharmacy professionals in Albania have the necessary skills to dispense antibiotics appropriately without a prescription. The findings will help shape future educational initiatives among pharmacists in Albania. In addition, whether there is a need to change or re-enforce current laws to improve future antibiotic utilization.

We believe this is the first time that such research activities have been undertaken among Balkan countries. Consequently, we believe our findings will be of interest to the authorities in Albania as well as other countries with similar rates of self-purchasing and co-payments. In view of this, the aim of this study is to analyze pharmacists' knowledge, perception and attitudes towards the dispensing antibiotics without a prescription in Albania.

\section{Materials and Method}

\subsection{Study design and setting}

A qualitative cross-sectional survey was conducted across all regions of Albania. The survey included only pharmacists practicing their profession in community pharmacies, who were members of regulatory bodies including the National Center of Licensing (24), which is obliged to register all pharmacies practicing in Albania (25).

\subsection{Sampling}

A random sample of community pharmacists practicing were targeted. The sample size was determined based on a confidence limit of $95 \%$ and a precision measure of $5 \%$, calculated with Open Epi Version 3.01. With the database of the Pharmacist's Order of Albania showing there were 2400 community pharmacists currently practicing, a sample size of 370 pharmacists was considered adequate for the study.

\subsection{Questionnaire}

The questionnaire, which was created and analyzed in Epi Info 7.1.3.10 software, was based on a literature review of similar qualitative interviews. The initial content was subsequently validated among three pharmacists and one infectious diseases physician to make sure the questions were clear, meaningful and not too long. Following this, a pilot study was conducted among 20 pharmacists to identify any problems including any ambiguity or concerns with any question, and these were addressed before administering the final questionnaire. The study took place between January to June 2014

The final list of topics, which were divided into different components, which included:

- Professional knowledge: questions were selected based on the most used antibiotic classes and the pharmacists' knowledge on the use and side effects of different antibiotics

- Regulation knowledge: Evaluation of pharmacists' knowledge of pertinent legislation regarding prescription procedures, if Albanian pharmacists had any information about treatment protocols and also regarding prescription regulations of executing and drug dispensing

- Attitudes regarding dispensing antibiotics without a prescription: Pharmacist's opinion and attitudes towards dispensing without prescription and understanding motives behind dispensing without prescription if this happens

- Opinion on the quality of prescriptions: Pharmacist opinion/judgment about the quality of prescription presented at their pharmacies.

The study was approved by the Faculty of Medicine, University of Medicine Tirana. The questionnaire was anonymous and verbal consent was elicited among all pharmacists before starting the questionnaire. 


\section{Results}

\subsection{Pharmacist characteristics}

A total of three hundred and seventy pharmacists took part in the study, with 319 pharmacists eventually completing the survey. The majority were female $(88,4 \%)$ aged between 24 and 30 years $(42.3 \%)$ or 31 to 40 years $(32.3 \%)$ and from the capital town, Tirana $(73.4 \%)$. Pharmacists with less than 5 years of experience were the largest group, comprising $31.3 \%$ of the participants.

\subsection{Pharmacist's knowledge about antibiotics and activities}

Most pharmacists $(74 \%)$ knew that antibiotics will kill the bacteria that cause infections, with $93 \%$ knowing that antibiotics were not effective against seasonal influenza with a similar number knowing that penicillins can cause anaphylactic shock (Table 2). However, only $13 \%$ stated that the main disadvantage of antibiotics is that they are ineffective against viruses. Other key components of knowledge including potential side-effects with antibiotics are captured in Table 3.

Table 2. Pharmacist's knowledge about antibiotics

\begin{tabular}{|c|c|c|}
\hline & Total Frequency (n) & Percent \\
\hline \multicolumn{3}{|c|}{ Antibiotics are not affective against which of the following pathogenic agent? } \\
\hline Bacteria & 14 & $4.4 \%$ \\
\hline Fungi & 102 & $32.0 \%$ \\
\hline Parasites & 120 & $37.6 \%$ \\
\hline Viruses & 83 & $26.0 \%$ \\
\hline \multicolumn{3}{|c|}{$\begin{array}{l}\text { Besides people, which animals are subject to exposure to antibiotics for therapeutic } \\
\text { treatment purposes? }\end{array}$} \\
\hline Rodents / laboratory rats & 208 & $65.2 \%$ \\
\hline Wildlife animals & 8 & $2.5 \%$ \\
\hline Farm animals & 97 & $30.4 \%$ \\
\hline Reptiles, cold-blooded animals & 6 & $1.9 \%$ \\
\hline \multicolumn{3}{|c|}{ Which of the following does not represent a mechanism of action for antibiotics? } \\
\hline Damaging the bacteria DNA & 83 & $26.0 \%$ \\
\hline Inactivate the bacteria in the host tissues & 176 & $55.2 \%$ \\
\hline Prevents bacteria propagation & 30 & $9.4 \%$ \\
\hline Interferes with cell wall formation & 30 & $9.4 \%$ \\
\hline \multicolumn{3}{|c|}{ Which of the following act by inhibiting protein synthesis? } \\
\hline Ciprofloxacin & 76 & $23.8 \%$ \\
\hline Flucloxacillin & 36 & $11.3 \%$ \\
\hline Chloramphenicol & 107 & $33.5 \%$ \\
\hline Trimethoprim & 100 & $31.3 \%$ \\
\hline \multicolumn{3}{|c|}{ Which of these antibiotics is the main cause anaphylactic shock? } \\
\hline Amoxicillin & 2 & $0.6 \%$ \\
\hline Ceftazidime & 13 & $4.1 \%$ \\
\hline Gentamycin & 9 & $2.8 \%$ \\
\hline Penicillin & 295 & $92.5 \%$ \\
\hline \multicolumn{3}{|l|}{ Antibiotic misuse cannot cause: } \\
\hline Serious side effects & 17 & $5.3 \%$ \\
\hline Stopping bacteria growing & 183 & $57.4 \%$ \\
\hline Antibacterial resistance & 22 & $6.9 \%$ \\
\hline
\end{tabular}




\begin{tabular}{|l|c|c|} 
Increase cost of treatment & 97 & $30.4 \%$ \\
\hline The use of antibiotics is not effective in which of the following cases? & 298 & $93.4 \%$ \\
\hline Seasonal flu & 1 & $0.3 \%$ \\
\hline Urinary tract infections & 19 & $6.0 \%$ \\
\hline Skin infections & 1 & $0.3 \%$ \\
\hline Ear infections & \multicolumn{2}{|l|}{} \\
\hline $\begin{array}{l}\text { What is the main disadvantage of antibiotics, the elimination of which researchers are } \\
\text { seeking solutions to increase their selectivity? }\end{array}$ & 41 & $12.9 \%$ \\
\hline Antibiotics are ineffective against viruses & 26 & $8.2 \%$ \\
\hline Antibiotics have side effects & 122 & $38.2 \%$ \\
\hline Prolonged use causes antimicrobial resistance & 130 & $40.8 \%$ \\
\hline Cannot distinguish between good bacteria and bad & 16 & $5.0 \%$ \\
\hline Which of the following is true? & 36 & $11.3 \%$ \\
\hline Antibiotics have no side effects & 32 & $10.0 \%$ \\
\hline Antibiotics increase immunity & 235 & $73.7 \%$ \\
\hline Antibiotics cause diarrhoea and vomiting & \multicolumn{2}{|l}{} \\
\hline Antibiotics kill all bacteria that cause infection & 45 & $14.1 \%$ \\
\hline Which of the following is true? & 129 & $40.4 \%$ \\
\hline Augmentin causes hepatic disease in men & 127 & $39.8 \%$ \\
\hline New Classes of antibiotics are discovered every year & 18 & $5.6 \%$ \\
\hline Macrolides do not cause hepatotoxicity & \\
\hline Hepatitis A is treated with ciprofloxacin & & \\
\hline
\end{tabular}

\subsection{Evaluation on legislation and guidance on antibiotic use}

More than half of pharmacists knew that colds are caused by viruses and cannot be treated with antibiotics, although the majority (93\%) had previously stated that antibiotics are not effective against seasonal influenza (Table 2). Few pharmacists $(5 \%)$ believed that patients asking for antibiotics without a prescription does not affect the rate of growth of AMR (Table 3). However, $18 \%$ believed that if a cold lasts for more than 4 days an antibioitic can bring a patient back to work, with $13 \%$ believing a high temperature and sweating can be prevented by broad spectrum antibioitics (Table 3 ). A concern is that the majority of pharmacists $(58 \%)$ admitted they were unaware of treatment protocols potentially involving antibiotics, with $93 \%$ admitting they had no treatment protocols to consult in their daily work (Table 3 ). $11 \%$ of pharmacists also believed antibiotics should be given without a prescription. 
Table 3. Evaluation on treatment knowledge and dispensing

\begin{tabular}{|c|c|c|}
\hline Questions and replies & $\begin{array}{l}\text { Frequency } \\
\text { (N) }\end{array}$ & $\%$ \\
\hline \multicolumn{3}{|c|}{$\begin{array}{l}\text { According to you, which among the following factors does not affect the rate of growth of } \\
\text { antimicrobial resistance? }\end{array}$} \\
\hline Not respecting physician recommendations when taking antibiotics & 14 & $4.4 \%$ \\
\hline Patient asks for antibiotics without prescription & 17 & $5.3 \%$ \\
\hline Patient does not take any antibiotics & 263 & $82.4 \%$ \\
\hline Patient chooses the preferred antibiotic & 22 & $6.9 \%$ \\
\hline \multicolumn{3}{|c|}{ Which of the following options about inappropriate use of antibiotics is right? } \\
\hline $\begin{array}{l}\text { When cold lasts more than } 4 \text { days, use of antibiotics can bring the patient } \\
\text { back to work }\end{array}$ & 56 & $17.6 \%$ \\
\hline Colds are caused by viruses, and cannot be treated with antibiotics & 173 & $54.2 \%$ \\
\hline Money can be saved when using left-over antibiotics & 35 & $11 \%$ \\
\hline $\begin{array}{l}\text { High temperature and sweating can be prevented if broad spectrum } \\
\text { antibiotics are used }\end{array}$ & 42 & $13.2 \%$ \\
\hline \multicolumn{3}{|l|}{ Do you know what treatment protocols are? } \\
\hline Yes & 130 & $42.3 \%$ \\
\hline No & 184 & $57.7 \%$ \\
\hline \multicolumn{3}{|l|}{ Do you have the treatment protocols? } \\
\hline Yes & 22 & $7 \%$ \\
\hline No & 294 & $93 \%$ \\
\hline \multicolumn{3}{|l|}{ Should antibiotics be given without prescription? } \\
\hline Yes & 34 & $10.7 \%$ \\
\hline No & 283 & $89.3 \%$ \\
\hline \multicolumn{3}{|c|}{ A patient comes to your pharmacy asking for 3 tablets of co-amoxiclav what do you do? } \\
\hline It happened, I sold them advising them how to use the antibiotic. & 106 & $33.2 \%$ \\
\hline It happened, I didn't give them, warning about the effects & 155 & $48.6 \%$ \\
\hline It didn't happen but I would give them advising how to use the antibiotic. & 35 & $11 \%$ \\
\hline It didn't happen, but I wouldn't give them warning about the effects. & 21 & $6.6 \%$ \\
\hline \multicolumn{3}{|l|}{ Are there antibiotics that can be given without prescription? } \\
\hline Yes & 55 & $17.4 \%$ \\
\hline No & 262 & $82.6 \%$ \\
\hline \multicolumn{3}{|c|}{$\begin{array}{l}\text { A patient appears in your pharmacy to return some leftover antibiotics unused from a } \\
\text { previous therapy: }\end{array}$} \\
\hline It happened, but I didn't take them & 248 & $77.7 \%$ \\
\hline It happened and I took them & 27 & $8.5 \%$ \\
\hline It happened, but I wouldn't take them & 10 & $3.1 \%$ \\
\hline It didn't happen, but I wouldn't take them & 32 & $10 \%$ \\
\hline
\end{tabular}

When asked how they would react if a patient presented to their pharmacy asking for 3 antibiotic tablets, for example 3 co-amoxiclav tablets, nearly half $(49 \%)$ stated that such an event has happened but they didn't give the patient antibiotics explaining about their risks. However, a third had dispensed antibiotics advising patients on their use (Table 3 ). $78 \%$ stated that they would not take leftover antibiotics from previous treatment courses. 
Over $70 \%$ of pharmacists agreed that if they did not give to the patient antibiotics without prescription, they will turn to the nearest pharmacy to get them.

3.4 Pharmacist's opinion and attitudes in critical antibiotics dispensing cases

The majority of pharmacists $(81 \%)$ had concerns that antibiotics appear not to be prescribed in the right way, with the greatest threat coming from physicians $(69 \%)$. There are also concerns with self purchasing based on current pharmacists' experience (31\%) (Table 4).

Table 4. Pharmacist's opinion and attitudes in critical antibiotic dispensing cases

\begin{tabular}{|c|c|c|}
\hline Questions and replies & $\begin{array}{l}\text { Frequency } \\
\text { (N) }\end{array}$ & $\%$ \\
\hline \multicolumn{3}{|c|}{ According to the prescription coming to your pharmacy, are antibiotics prescribed in the right way? } \\
\hline Yes & 60 & $19.4 \%$ \\
\hline No & 257 & $80.6 \%$ \\
\hline \multicolumn{3}{|c|}{$\begin{array}{l}\text { Analyzing the quality of the antibiotic prescriptions coming to your pharmacy, do you think that the } \\
\text { bigger threat is due to: }\end{array}$} \\
\hline $\begin{array}{l}\text { Giving antibiotics without prescription only based on pharmacists' } \\
\text { experience }\end{array}$ & 110 & $31.3 \%$ \\
\hline Antibiotics prescribed (dose, form...) from general practitioners & 219 & $68.7 \%$ \\
\hline
\end{tabular}

\section{Discussion}

We are aware that published studies have assessed community pharmacists' attitudes towards antibiotic dispensing, microbial resistance and their misuse, knowledge and attitudes towards URTIs as well as dispensing antibiotics without a prescription $(3,9,26-28)$. However, we believe this is one of the first studies to comprehensively test pharmacists' knowledge regarding all aspects of antibiotic use across key domains, particularly important in countries with high rates of self-purchasing.

This study showed variable knowledge among community pharmacists. Encouragingly, the majority $(93 \%)$ knew that antibiotics are ineffective against influenza and that penicillins can cause anaphylactic shock, with three quarters believing antibiotics kill bacteria that cause infections and just over half that colds are caused by viruses and should not be treated with antibiotics (Table 2). In addition, only $7 \%$ believed antibiotic misuse cannot cause AMR and $5 \%$ that antibiotics have no side effects. This compares favourably with Eslami et al where $86 \%$ of pharmacists in Iran gave correct responses when URTIs persist after 10 to 14 days and more than half believed most are viral in origin (6). However, an appreciable improvement when compared with pharmacists in India who had very limited understanding of AMR (14) and favourably with Vietnam where in only $36 \%$ of occasions did pharmacists provide advice on the management of ARIs in children in accordance with national guidelines (29), and generally drug sellers' knowledge of antibiotics and AMR was low (10). Similar concerns were also seen in China (3).

However, only a minority of pharmacists in our study stated antibiotics are not effective against viruses, their prolonged use causes AMR and that antibiotics cannot cause serious side-effects. The latter is perhaps not surprising as generally there was limit knowledge about the side-effects of antibiotics in our study. This is similar to Ahmad et al who also showed limited knowledge about antibiotics and AMR among pharmacy students (23), with similar concerns among pharmacy students in Pakistan (5).

Encouragingly, a high percentage of pharmacists stated they should not dispense an antibiotic without a prescription (Table 3 ), comparing favourably with other similar countries $(3,7,14,16,29)$ However, there were concerns with a third of respondents admitted selling even just 3 co-amoxiclav tablets.

There are also concerns about the lack of any protocols among pharmacists to direct the treatment of patients with infections presenting to pharmacists in Albania. This is unlike the Republic of Srpska, Bosnia and Herzegovina, where 'The Guideline for counselling patients in the pharmacy' booklet was launched in 2013 to aid pharmacy personnel in making appropriate decisions and giving advice (18). 
As a result, we believe there are a number of potential ways forward for the authorities and other key organisations in Albania to enhance the rational use of antibiotics. These include:

- Initiate campaigns to sensitize patients on the optimal use of antibiotics as well as educate them that ARIs are mainly viral in origin, similar to other countries $(2,4)$. This is particularly important for patients with lower and middle education as they are the most likely to try and self purchase antibiotics $(12,14,16,26)$. This year for the first time in Albania (2016/ 2017), a small campaign targeting pharmacists and patients has been undertaken in community pharmacies, including a poster with advice on how to use and dispense antibiotics

- Evaluating the impact of the current campaign targeting pharmacists and patients in Albania to guide future initiatives

- Appraising the content of current educational programmes among pharmacy students, as well as among community pharmacists in Albania to address information gaps highlighted in our study

- Develop treatment protocols with key stakeholder groups surrounding the optimal management of community infections

- Greater enforcement of the legislation regarding illegal selling of antibiotics without a prescription $(3,9,11)$. This has worked well in other countries $(2,13)$, and could include fines for inappropriate dispensing as seen for instance in the Republic of Srpska (18). The new online prescription system, "e-Prescription" (30), coupled with the new fiscal reforms, should facilitate the tracking of antibiotics sold illegally in Albania, as well as track current prescribing practices to address concerns

- Further education among physicians to address concerns

- Reserve particulalry second line antibiotics for hospital use only

There are limitations with this study including the fact that not all pharmacists who agreed to take part completed the questionnaire. In addition, most respondents were from the capital city, Tirana.

However, the majority of community pharmacists in Albania work in Tirana. In addition, we employed a robust methodology for the questionnaire and sample size. We accept though that pharmacists may not be fully truthful in their replies as the responses are declarative and not checked. Consequently, the findings may be worse than seen. Despite these limitations, we believe based on an $86 \%$ response rate that our findings are valid and may be of interest to countries outside of Albania with similar characteristics.

\section{Conclusions}

There was variable knowledge about antibiotics among community pharmacists in Albania. This coupled with the lack of treatment guidelines, current high rates of self-purchasing of antibiotics, as well as concerns with physician prescribing habits, will increase AMR rates unless addressed.

Potential initiatives to improve future dispensing of antibiotics in Albania could include updating pharmacists' professional knowledge building on examples in countries including the Republic of Srpska. In addition, educating the $r$ public not to expect an antibiotic for self-limiting diseases, building on recent campaigns. Additional measures to reduce self-purchasing could also include fines for pharmacists for any illegal selling of antibiotics.

The vital role that antibiotics play in reducing morbidity and mortality, coupled with patient safety, should be at the forefront of interactions between patients and community pharmacists as part of ongoing antimicrobial stewardship programmes. Such considerations should reduce the need to dispense antibiotics for suspected viral infections. Such activities will maintain, or even grow, the position of community pharmacists as a key stakeholder in improving the health of patients in Albania. These are plans for the future.

\section{Ethical considerations and conflicts of interest}

The questionnaire was anonymous and verbal consent was elicited among all pharmacists before starting the questionnaire. The study was performed voluntarily by the researchers with no external funding. Overall:

- Funding: None 
- Conflicts of interest: None

- Ethical approval: Not required

\section{References}

1. Morgan DJ, Okeke IN, Laxminarayan R, Perencevich EN, Weisenberg S. Non-prescription antimicrobial use worldwide: a systematic review. The Lancet Infectious diseases. 2011;11(9):692701.

2. Godman B, Fadare J, Kibuule D, Irawati L, Mubita M, Ogunleye et al. Initiatives across countries to reduce antibiotic utilization and resistance patterns; impact and implications. Drug Resistance in Bacteria, Fungi, Malaria, and Cancer - Arora, Sajid, \& Kalia Eds Publisher Springer Nature ISBN 978-3-319-48682-6 Available at URL:

https://purestrathacuk/portal/en/publications/initiatives-across-countries-to-reduce-antibiotic-utilizationand-resistance-patterns(bb445446-fd1d-47b3-8f91-def5d9e5e3db)/exporthtml.

3. Chang J, Ye D, Lv B, Jiang M, Zhu S, Yan K, et al. Sale of antibiotics without a prescription at community pharmacies in urban China: a multicentre cross-sectional survey. The Journal of antimicrobial chemotherapy. 2017;72(4):1235-42.

4. $\quad$ Llor C, Bjerrum L. Antimicrobial resistance: risk associated with antibiotic overuse and initiatives to reduce the problem. Therapeutic advances in drug safety. 2014;5(6):229-41.

5. Saleem Z, Saeed H, Ahmad M, Yousaf M, Hassan HB, Javed A, et al. Antibiotic SelfPrescribing Trends, Experiences and Attitudes in Upper Respiratory Tract Infection among Pharmacy and Non-Pharmacy Students: A Study from Lahore. PloS one. 2016;11(2):e0149929.

6. Eslami N, Eshraghi A, Vaseghi G, Mehdizadeh M, Masjedi M, Mehrpooya M. Pharmacists' Knowledge and Attitudes Towards Upper Respiratory Infections (URI) in Iran: A Cross Sectional Study. Rev Recent Clin Trials. 2016;11(4):342-5.

7. Belkina T, Duvanova N, Karbovskaja J, Tebbens JD, Vlcek J. Antibiotic use practices of pharmacy staff: a cross-sectional study in Saint Petersburg, the Russian Federation. BMC Pharmacology \& Toxicology. 2017;18:11.

8. Gebeyehu E, Bantie L, Azage M. Inappropriate Use of Antibiotics and Its Associated Factors among Urban and Rural Communities of Bahir Dar City Administration, Northwest Ethiopia. PloS one. 2015;10(9):e0138179.

9. Soumya R, Devarashetty V, Jayanthi CR, Sushma M. Drug dispensing practices at pharmacies in Bengaluru: A cross-sectional study. Indian Journal of Pharmacology. 2016;48(4):360-4. 10. Nga DTT, Chuc NTK, Hoa NP, Hoa NQ, Nguyen NTT, Loan HT, et al. Antibiotic sales in rural and urban pharmacies in northern Vietnam: an observational study. BMC Pharmacology \& Toxicology. 2014;15:6-.

11. HOXHA I, Malaj A, TAKO R, MALAJ L. Survey on how antibiotics are dispensed in community pharmacies in Albania. International Journal of Pharmacy and Pharmaceutical Sciences. 2015;7(7):449-50.

12. Jorgji K, Bebeci E, Apostoli P, Apostoli A. Evaluation of use of antibiotics without prescription among young adults in Albania case study: Tirana and Fier District. Hippokratia. 2014;18(3):217-20.

13. Santa-Ana-Tellez Y, Mantel-Teeuwisse AK, Dreser A, Leufkens HG, Wirtz VJ. Impact of overthe-counter restrictions on antibiotic consumption in Brazil and Mexico. PloS one. 2013;8(10):e75550.

14. Barker AK, Brown K, Ahsan M, Sengupta S, Safdar N. What drives inappropriate antibiotic dispensing? A mixed-methods study of pharmacy employee perspectives in Haryana, India. BMJ open. 2017;7(3):e013190.

15. Ocan M, Obuku EA, Bwanga F, Akena D, Richard S, Ogwal-Okeng J, et al. Household antimicrobial self-medication: a systematic review and meta-analysis of the burden, risk factors and outcomes in developing countries. BMC public health. 2015;15:742.

16. Miller R, Goodman C. Performance of retail pharmacies in low- and middle-income Asian settings: a systematic review. Health Policy and Planning. 2016;31(7):940-53.

17. Hoxha I, Malaj A, Malaj L. Antibiotic use in Albania between 2011 and 2012. Journal of infection in developing countries. 2015;9(1):94-8.

18. Markovic-Pekovic V, Grubisa N, Burger J, Bojanic L, Godman B. Initiatives to Reduce Nonprescription Sales and Dispensing of Antibiotics: Findings and Implications. J Res Pharm Pract. 2017;6(2):120-5.

19. FIP. FIP statement of policy - control of antimicrobial medicines resistance (AMR). Available from URL: http://www.fip.org/www/uploads/database file.php?id=289\&table id 
20. WHO. The role of pharmacist in encouraging prudent use of antibiotics and averting antimicrobial resistance: a review of policy and experience. Available at URL:

http://www.euro.who.int/ data/assets/pdf file/0006/262815/The-role-of-pharmacist-in-encouragingprudent-use-of-antibiotics-and-averting-antimicrobial-resistance-a-review-of-policy-and-experienceEng.pdf?ua $=1$

21. WHO. Antimicrobial Medicines Consumption (AMC) Network. 2017. Available at URL: http://www.euro.who.int/en/publications/abstracts/antimicrobial-medicines-consumption-amc-network.amc-data-20112014-2017

22. Versporten A, Bolokhovets G, Ghazaryan L, Abilova V, Pyshnik G, Spasojevic T, et al. Antibiotic use in eastern Europe: a cross-national database study in coordination with the WHO Regional Office for Europe. The Lancet Infectious diseases. 2014;14(5):381-7.

23. Ahmad A, Khan MU, Moorthy J, Jamshed SQ, Patel I. Comparison of knowledge and attitudes about antibiotics and resistance, and antibiotics self-practicing between Bachelor of Pharmacy and Doctor of Pharmacy students in Southern India. Pharmacy practice. 2015;13(1):523. 24. Albania. Law No. 105/2014, amended, "On drugs and pharmaceutical service". Available at URL: http://www.qbz.gov.al/Ligje.pdf/barnat/LIGJ 105 2014.pdf.

25. Pharmacists. Order of Albania. LIGJI NR. 9150, DATË 30.10.2003 PËR URDHRIN E FARMACISTËVE NE REPUBLIKËN E SHQIPËRISË (Law No. 9150, date 30.10.2003, amended "On Pharmacists Order in the Republic of Albania". Available at URL:

http://www.ufsh.org.al/legislation/ligji-nr-9150-date-30102003-per-urdhrin-e-farmacisteve-nerepubliken-e-shqiperise

26. Hadi MA, Karami NA, Al-Muwalid AS, Al-Otabi A, Al-Subahi E, Bamomen A, et al. Community pharmacists\&\#x2019; knowledge, attitude, and practices towards dispensing antibiotics without prescription (DAwP): a cross-sectional survey in Makkah Province, Saudi Arabia. International Journal of Infectious Diseases.47:95-100.

27. Roque F, Soares S, Breitenfeld L, Gonzalez-Gonzalez C, Figueiras A, Herdeiro MT.

Portuguese Community Pharmacists' Attitudes to and Knowledge of Antibiotic Misuse: Questionnaire Development and Reliability. PloS one. 2014;9(3):e90470.

28. Neda E, Azadeh E, Golnaz V, Mona M, Moein M, Maryam M. Pharmacists\&\#39; Knowledge and Attitudes Towards Upper Respiratory Infections (URI) in Iran: A Cross Sectional Study. Reviews on Recent Clinical Trials. 2016;11(4):342-5.

29. Chuc NT, Larsson M, Falkenberg T, Do NT, Binh NT, Tomson GB. Management of childhood acute respiratory infections at private pharmacies in Vietnam. The Annals of pharmacotherapy. 2001;35(10):1283-8.

30. Albania. Shëndetësia Elektronike, nga Vizion në Realitet (Electronic Health, Ministry of Health, Tirana, Albania, 30 May 2015). Available at URL:

http://www.shendetesia.gov.al/al/newsroom/lajme/shendetesia-elektronike-nga-vizion-ne-realitet 